\title{
ENERGY-DEPENDENT UPTAKE OF BENZOMORPHANS BY LEUKOCYTES
}

\author{
Fedor Medzihradsky, Michael J. Marks and Edward A. Carr, JR. \\ Departments of Biological Chemistry and Pharmacology and the Upjohn Center for Clinical Pharma- \\ cology, The University of Michigan, Ann Arbor, Mich. 48104, U.S.A.
}

(Received 31 August 1971; accepted 17 December 1971)

\begin{abstract}
Pentazocine rapidly enters the brain after i.p. administration to rats. Using leukocytes as model mammalian cells, the uptake of this drug was studied. Morphologically intact and metabolically active rat leukocytes accumulated pentazocine in vitro against a concentration gradient. The 6- to 10-fold concentration of the drug was dependent upon the presence of glucose in the incubation medium and was strongly affected by metabolic inhibitors present in millimolar concentrations. The uptake showed saturation kinetics in the concentration range of $1.7-14 \times 10^{-5} \mathrm{M}$ pentazocine and was competitively inhibited by analogue benzomorphan derivatives. Ouabain as well as sodium-free extracellular media had no effect on the uptake of pentazocine. The transport system for pentazocine in the leukocyte apparently differs from the relatively nonspecific amine pump which accumulates various organic bases in the blood platelet.
\end{abstract}

Pentazocine, [1,2,3,4,5,6-hexahydro-6,11-dimethyl-3-(3-methyl-2-butenyl)-2,6-methano-3-benzazocine-8-ol], a clinically used benzomorphan derivative, has been reported to be a potent analgesic in man, with a rapid onset of action. ${ }^{1}$ In agreement with the latter clinical observation, it was found ${ }^{2}$ that pentazocine penetrates biological membranes quite easily and the blood-brain barrier seemed to have little restricting effect on the entry of this compound into the brain. Peak concentrations of pentazocine in plasma and brain after i.p. administration were obtained at 2 and $10 \mathrm{~min}$, respectively. Furthermore, over the range of $25-100 \mathrm{mg} / \mathrm{kg}$ of injected pentazocine, the ratio of concentration in plasma to concentration in brain remained unchanged. After this demonstration of a pronounced and rapid exchange of the drug between compartments separated by biological membranes, it was of interest to study the cellular mechanism of this transport. In selecting a biological system, leukocytes were chosen as conveniently available, morphologically typical mammalian cells. If a correlation between the biochemical behavior of leukocytes and that of other tissue cells were demonstrated, leukocytes could be used as model cells for the study of selected biochemical processes in organs not easily accessible through techniques of tissue sampling.

\section{EXPERIMENTAL PROCEDURES}

Materials. The sources of drugs were: Winthrop (pentazocine, cyclazocine) and Smith, Kline \& French (phenazocine). Etazocine was kindly provided by Dr. J. E. Villarreal, Department of Pharmacology, The University of Michigan. Plasmagel, an artificial medium of suitable density used for the separation by sedimentation of 
leukocytes and erythrocytes, was obtained from Laboratoire Roger Bellon, Neuilly, France. All common chemicals were of reagent grade.

Separation and characterization of leukocytes. Male Sprague-Dawley rats weighing $300 \mathrm{~g}$ were used. Blood was obtained from the venae cavae of the lightly anesthetized (diethylether) rats. An average of $12 \mathrm{ml}$ blood was collected from each animal. Sodium heparinate was used as an anticoagulant. To $6 \mathrm{ml}$ of blood in 10-ml tubes was added $2 \mathrm{ml}$ Plasmagel; the tubes were gently mixed by inversion and incubated for $45 \mathrm{~min}$ at $37^{\circ}$. The supernatant, containing the leukocytes, was carefully removed from the erythrocyte layer and centrifuged for $2 \mathrm{~min}$ at $500 \mathrm{~g}$ in the cold $\left(2^{\circ}\right)$. The pellet, containing the leukocytes and some contaminating erythrocytes, was then suspended in $2 \mathrm{ml}$ of the incubation medium at $37^{\circ}$ and the remaining red blood cells lysed by the rapid and forceful addition of $6 \mathrm{ml} \mathrm{H}_{2} \mathrm{O}$ from a syringe. After mixing for $5 \mathrm{sec}$ by inversion, $2 \mathrm{ml}$ of $3.4 \% \mathrm{NaCl}$ was added and the mixture centrifuged for 2 $\mathrm{min}$ at $500 \mathrm{~g}$ in the cold. Finally, the pellet containing the leukocytes was resuspended in the incubation medium.

The yield of cells was determined by manual cell counting using an AO Spenser Bright Line hemacytometer. Protein was determined according to Lowry et al. ${ }^{3}$ Hemoglobin was estimated by measuring cyanomethemoglobin at $450 \mathrm{~nm} .{ }^{4}$ The leukocyte preparation was examined microscopically using Wright's stain. For the determination of the cellular concentrations of sodium and potassium, the thoroughly washed leukocytes were digested with $70 \% \mathrm{HNO}_{3}$ in polypropylene tubes for $30 \mathrm{~min}$ at $80^{\circ}$. After the appropriate dilution with $\mathrm{LiCl}$ standard, the measurements were performed in an IL flame photometer. Oxygen uptake was measured in air, using a Gilson differential respirometer.

Incubation, extraction and gas chromatography of drugs. The incubations were performed at $37^{\circ}$. The basic incubation medium contained final millimolar concentrations of: $\mathrm{NaCl}, 154 ; \mathrm{KCl}, 2.68 ; \mathrm{MgCl}_{2}, 1 \cdot 15 ; \mathrm{CaCl}_{2}, 1.78 ; \mathrm{NaHCO}_{3}, 11.9 ; \mathrm{KH}_{2}$ $\mathrm{PO}_{4}, 0 \cdot 37$; and glucose, $5 \cdot 55$. The $\mathrm{pH}$ of the medium was adjusted to $7 \cdot 4$ with $\mathrm{HCl}$.

The extraction of the drugs and their gas chromatographic determination were performed essentially as described previously. ${ }^{5}$ To insure membrane damage, the cellular preparation was subjected to repeated freezing $\left(-70^{\circ}\right)$ and thawing prior to the extraction. The $\mathrm{pH}$ of $1 \mathrm{ml}$ of the cellular suspension was adjusted to 8.5 with $0.05 \mathrm{~N} \mathrm{NaOH}$ and the drugs were extracted with $10 \mathrm{ml}$ benzene. $8-\mathrm{ml}$ aliquots were evaporated and used for the gas chromatographic analysis. In most experiments cyclazocine (see Fig. 7) was used as the internal gas chromatographic standard.

\section{RESULTS}

Characterization and viability of the leukocyte preparation. The yield of leukocytes ranged from $5 \times 10^{6}$ to $1 \times 10^{7}$ cells $/ \mathrm{ml}$ of rat blood. A cell number of $1 \times 10^{6}$ corresponded to approximately $50 \mu \mathrm{g}$ protein. The average leukocyte preparation contained 80 per cent lymphocytes and 20 per cent granulocytes. Microscopic examination after the lysis step showed absence of intact erythrocytes and the hemoglobin concentration was below our detection limit $\left(0.4\right.$ per cent). The $\mathrm{Na}^{+}$and $\mathrm{K}^{+}$content of the leukocytes averaged to 1.2 and $6.3 \mathrm{~m}$-equiv. $/ 10^{8}$ cells. The oxygen consumption at $37^{\circ}$ of the suspension of leukocytes $\left(10^{7}\right.$ cells $\left./ \mathrm{ml}\right)$ in $150 \mathrm{mM}$ Krebs-Ringer phosphate buffer ( $\mathrm{pH} 7 \cdot 4$ ) was $5-7 \mu \mathrm{l} / 10^{7}$ cells/hr. The consumption was linear over a 


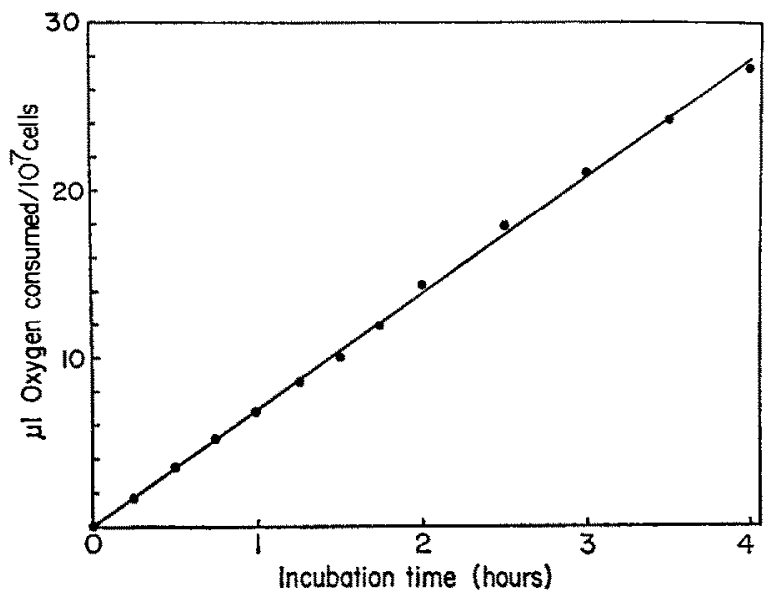

Fig. 1. Oxygen uptake of the leukocyte preparation. Suspensions of leukocytes $\left(10^{7}\right.$ cells $\left./ \mathrm{ml}\right)$ in the incubation medium (pH 7.4) described in the text were incubated at $37^{\circ}$ for the indicated lengths of time in 15-ml vessels of a Gilson respirometer in air. The results of a representative experiment are given. The points represent averages of two individual measurements. The mean \pm standard deviation for eight experiments was $6 \cdot 1 \pm 1 \cdot 5 \mu 1 \mathrm{O}_{2} / 10^{7}$ cells $/ \mathrm{hr}$.

period of $4 \mathrm{hr}$ (Fig. 1). During this time period, the cell count and the initial ratio of $\mathrm{Na}^{+} / \mathrm{K}^{+}$remained also constant. In addition, a microscopic examination of the stained cellular preparation after $4 \mathrm{hr}$ of incubation at $37^{\circ}$ in the Krebs-Ringer solution or in the incubation medium used in other experiments (see below) revealed no change in the appearance of the cells.

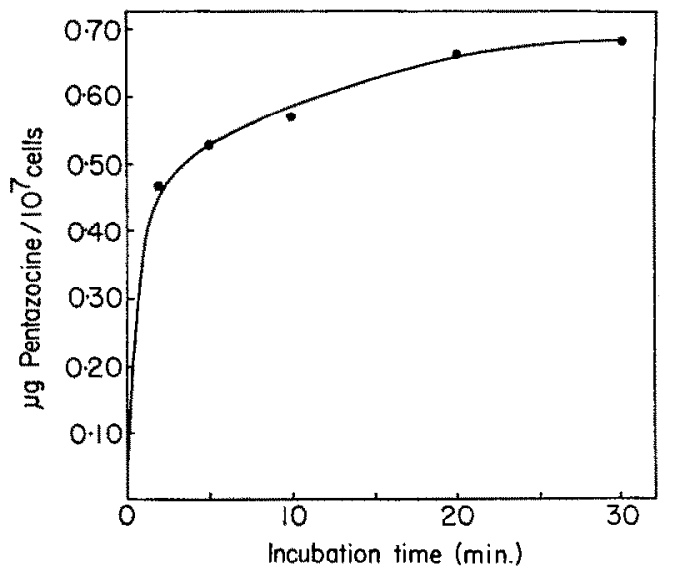

FIG. 2. Uptake in vitro of pentazocine by rat leukocytes. Leukocytes were incubated at $37^{\circ}$ for the various times indicated, using the incubation medium ( $\mathrm{pH} \mathrm{7.4)} \mathrm{described} \mathrm{in} \mathrm{the} \mathrm{text.} \mathrm{In} \mathrm{addition,} \mathrm{the}$ medium contained an initial concentration of $3.5 \times 10^{-5} \mathrm{M}(10 \mu \mathrm{g} / \mathrm{ml})$ pentazocine. The extraction of the drug and its estimation by gas chromatography were as described in the text. The results of a typical experiment are given. The points represent averages of results obtained from three individual incubations using the same preparation of leukocytes. The standard deviation about these averages did not exceed 9 per cent of the mean value. The mean uptake of pentazocine in 70 separate incubations was $87.3 \pm 25 \cdot 2 \mu \mathrm{g} / \mathrm{g}$ of cells. 


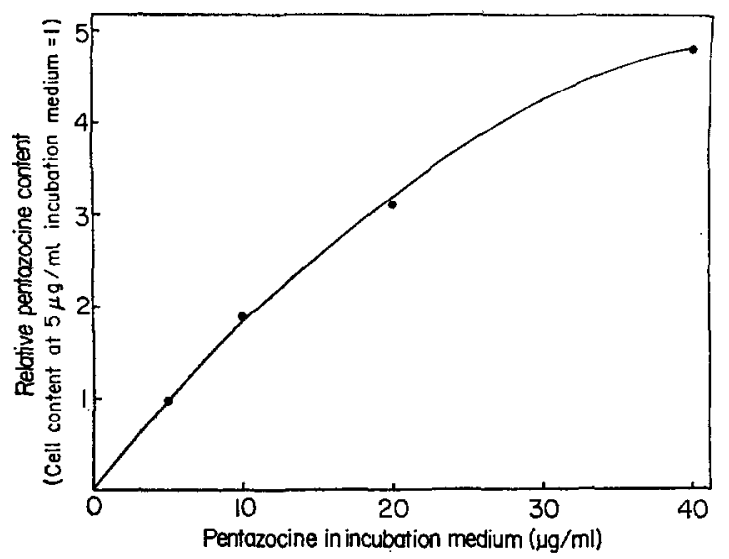

FIG. 3. Concentration dependence of the uptake of pentazocine by rat leukocytes. Leukocytes were incubated at $37^{\circ}$ for 30 min in the medium (pH 7.4) described in the text. In addition, the medium contained various concentrations of pentazocine ranging from 1.7 to $14 \times 10^{-5} \mathrm{M}$. The extraction of the drug and its estimation by gas chromatography were as described in the text. At each concentration of pentazocine, three experiments were carried out, except with $10 \mathrm{ug} / \mathrm{ml}$ for which six experiments were performed. The standard deviations about the mean values ranged from 0 to 13 per cent.

Uptake of pentazocine by leukocytes. The leukocytes, when incubated at $37^{\circ}$ in a medium (pH 7.4) containing glucose and pentazocine $\left(1.7-14 \times 10^{-5} \mathrm{M}\right)$, accumulated the drug 6- to 10-fold. After incubation in a medium containing $10 \mu \mathrm{g} / \mathrm{ml}$ $\left(3.5 \times 10^{-5} \mathrm{M}\right)$ of pentazocine, the average concentration of the drug at saturation was $87.3 \mu \mathrm{g} / \mathrm{g}$ of cells. The initial rate of uptake was very rapid (Fig. 2). More than 70 per cent of the final cellular drug concentration was reached within the first $2 \mathrm{~min}$. The uptake of pentazocine showed saturation kinetics (Fig. 3). When the reciprocal concentration of pentazocine in the incubation medium was plotted against the

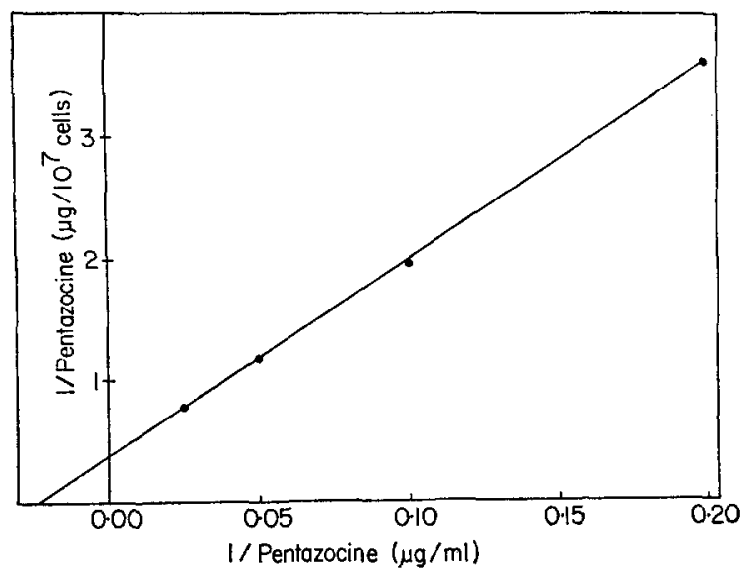

FIG. 4. Double reciprocal plot of the extra- and intracellular concentrations of pentazocine during the uptake of the drug by rat leukocytes. Abscissa, concentration of pentazocine in the incubation medium ordinate, amount of pentazocine taken up by $10^{7}$ cells at saturation $(30 \mathrm{~min})$. Experimental conditions were as described in the legend for Fig. 3. 
reciprocal amounts of the drug taken up by $10^{7}$ cells at saturation, a linear relationship was obtained (Fig. 4). From this graph, the apparent maximum possible concentration of pentazocine in leukocytes (intercept at the ordinate) and the half-maximum concentration of the drug in the medium necessary to achieve saturation (intercept at the abscissa) were determined. The values were $2.2 \mu \mathrm{g}\left(0.7 \times 10^{-8} \mathrm{moles}\right) / 10^{7}$ cells and $34.5 \mu \mathrm{g}\left(1.2 \times 10^{7} \mathrm{moles}\right) / \mathrm{ml}$ respectively. Methodological reasons prevented us from examining the linearity of the uptake prior to $2 \mathrm{~min}$. Therefore, as a reference point, the uptake at 30 min was chosen, at which time near saturation was reached (Fig. 2).

Glucose dependency of the uptake. When glucose was omitted from the incubation medium and the cells were preincubated for $2 \mathrm{hr}$ at $37^{\circ}$ in order to deplete the intracellular glucose content, the usual 6- to 10-fold accumulation of pentazocine diminished to 1.3-fold (Fig. 5). If glucose $\left(5.55 \times 10^{-3} \mathrm{M}\right)$ was added to the depleted cellular suspension, the uptake of the drug again increased (Fig. 5).

Effect of metabolic inhibitors. The uptake of pentazocine was inhibited by various metabolic inhibitors (Table 1) present in the concentration range of $1-5 \times 10^{-3} \mathrm{M}$, except $\mathrm{NaF}$, which was $30 \times 10^{-3} \mathrm{M}$ in the incubation medium. Whereas cyanide had no effect, the other compounds reduced the uptake considerably. Strongest inhibition ( 88 per cent) of the pentazocine transport was obtained with iodoacetamide.

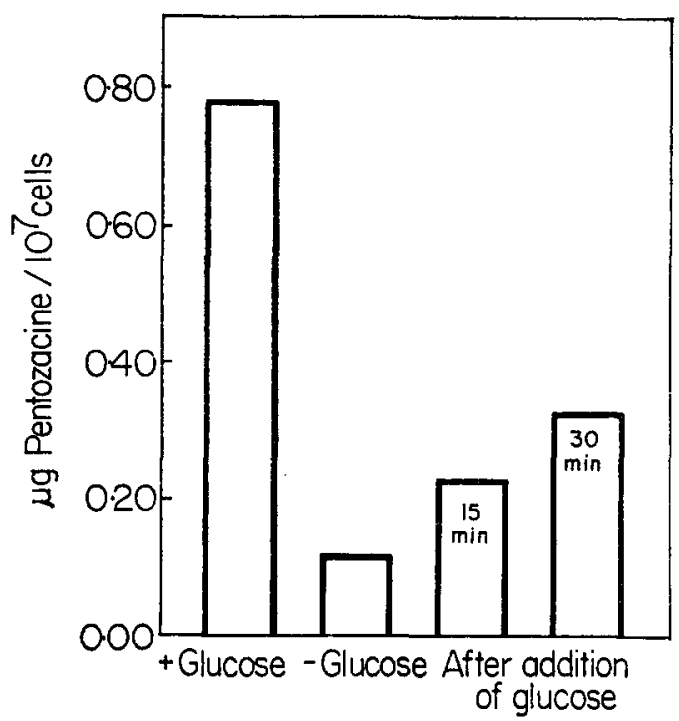

FIG. 5. Glucose dependency of the uptake of pentazocine by rat leukocytes. The first bar ( + Glucose) shows the uptake of pentazocine by leukocytes which were incubated at $37^{\circ}$ for $30 \mathrm{~min}$ in the incubation medium ( $\mathrm{pH} 7.4)$ described in the text. The medium contained glucose $\left(5.55 \times 10^{-3} \mathrm{M}\right)$ and pentazocine $\left(3.5 \times 10^{-5} \mathrm{M}\right)$. The second bar ( - Glucose $)$ represents experiments in which leukocytes were preincubated at $37^{\circ}$ for $2 \mathrm{hr}$ in a glucose-free medium, and then pentazocine $\left(3.5 \times 10^{-5}\right.$ M) was added. After reincubation for $30 \mathrm{~min}$, the cellular uptake of the drug was determined as described. The last two bars (After addition of glucose) represent the uptake of pentazocine by leukocytes at various times after the addition of glucose $\left(5.55 \times 10^{-3} \mathrm{M}\right)$ to the initially preincubated cellular preparation in a glucose-free medium. The additional steps were as described. The results of a representative experiment are given. The values represent averages of results obtained from three individual incubations using the same preparation of leukocytes. The standard deviation about these averages did not exceed 5 per cent of the mean value. The standard deviation for three experiments was 14.5 per cent. 
TABle 1. EFFeCt OF VARIOUS METABOLIC INHIBITORS ON THE UPTAKE OF PENTAZOCINE BY RAT LEUKOCYTES*

\begin{tabular}{lccc}
\hline \multicolumn{1}{c}{ Inhibitor } & $\begin{array}{c}\text { Conc. } \\
\text { in medium } \\
(\mathrm{mM})\end{array}$ & $\begin{array}{c}\text { Uptake of pentazocine } \\
(\mu \mathrm{g} \text { drug/107 cells })\end{array}$ & $\begin{array}{c}\% \\
\text { inhibition } \\
\text { of uptake }\end{array}$ \\
\hline Control & & $0.42 \pm 0.03$ & \\
Sodium cyanide & 2 & $0.42 \pm 0.07$ & 0 \\
Sodium azide & 2 & $0.31 \pm 0.02$ & 26.2 \\
Dinitrophenol & 2 & $0.24 \pm 0.04$ & $\mathbf{4 2 . 8}$ \\
Sodium fluoride & 30 & $0.20 \pm 0.02$ & 52.4 \\
Iodoacetamide & 3 & $0.07 \pm 0.03$ & $\mathbf{8 3 . 3}$ \\
\hline
\end{tabular}

* Rat leukocytes were preincubated with various inhibitors at $37^{\circ}$ for $30 \mathrm{~min}$ in the incubation medium (pH 7.4) described in the text. After the addition of pentazocine $\left(3.5 \times 10^{-3} \mathrm{M}\right)$, the tubes were incubated for an additional $30 \mathrm{~min}$ at $37^{\circ}$. The further treatment was as described in the text. The results \pm S.D. of six determinations are given.

Inhibition of pentazocine accumulation by analogue benzomorphan derivatives. In the presence of cyclazocine, etazocine and phenazocine, respectively, the uptake of pentazocine was considerably reduced (Fig. 6). The analogues, present at concentrations of $0.3-7 \cdot 3 \times 10^{-4} \mathrm{M}$, inhibited the uptake up to 90 per cent. Future work, which will include a more convenient methodological approach, should further reveal the kinetics of this inhibition. The structures of the benzomorphan derivatives in relation to pentazocine are shown in Fig. 7.

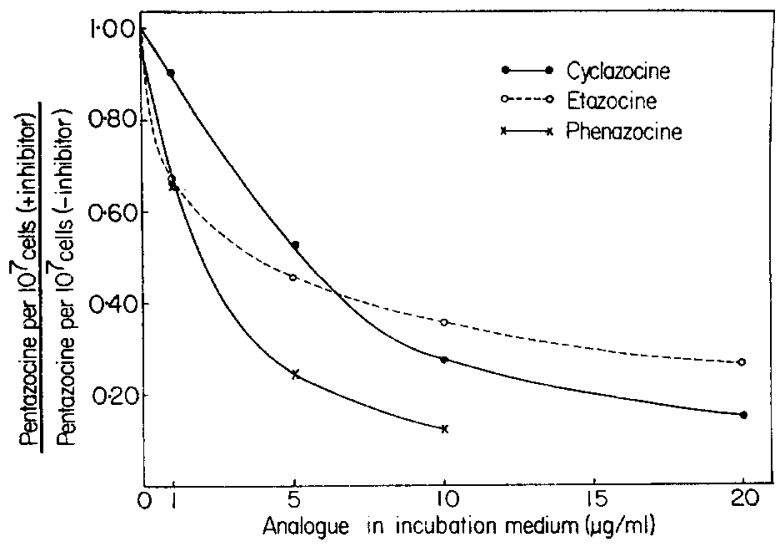

Fig. 6. Effect of analogous benzomorphans on the uptake of pentazocine by rat leukocytes. Leukocytes were incubated at $37^{\circ}$ for $30 \mathrm{~min}$ in the incubation medium ( $\mathrm{pH} \mathrm{7.4)} \mathrm{described} \mathrm{in} \mathrm{the} \mathrm{text.} \mathrm{The}$ medium contained pentazocine $\left(3.5 \times 10^{-5} \mathrm{M}\right)$ and in addition, cyclazocine, etazocine or phenazocine, respectively, in the concentration range of $3.4 \times 10^{-5}$ to $7.4 \times 10^{-4} \mathrm{M}$. The extraction of pentazocine and its estimation by gas chromatography were as described in the text. Whereas cyclazocine was generally used as the internal gas chromatographic standard, it was substituted by etazocine in experiments using cyclazocine as an inhibitor of the uptake. The results of a representative experiment are given. The values represent averages of results obtained from three individual incubations using the same preparation of leukocytes. The standard deviation about these averages did not exceed 5 per cent of the mean value. The standard deviation for three experiments was 9.5 per cent. 


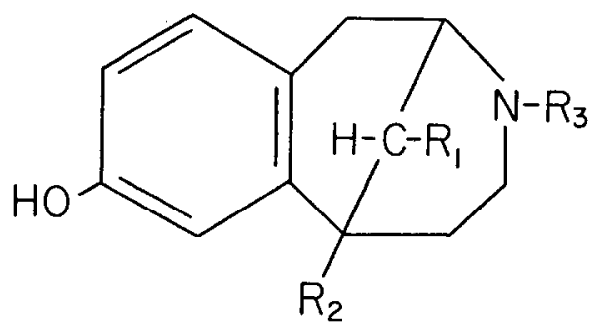

\begin{tabular}{|l|r|r|l|}
\hline Compound & $\mathrm{R}_{1}$ & $\mathrm{R}_{2}$ & \multicolumn{1}{|c|}{$\mathrm{R}_{3}$} \\
\hline Pentazocine & $-\mathrm{CH}_{3}$ & $-\mathrm{CH}_{3}$ & $-\mathrm{CH}_{2} \mathrm{CH}=\mathrm{C}\left(\mathrm{CH}_{3}\right)_{2}$ \\
\hline Cyclazocine & $-\mathrm{CH}_{3}$ & $-\mathrm{CH}_{3}$ & $-\mathrm{CH}_{2}-\triangleleft$ \\
\hline Phenazocine & $-\mathrm{CH}_{3}$ & $-\mathrm{CH}_{3}$ & $-\mathrm{CH}_{2} \mathrm{CH}_{2} \mathrm{C}_{6} \mathrm{H}_{5}$ \\
\hline Etazocine & $-\mathrm{C}_{2} \mathrm{H}_{5}$ & $-\mathrm{C}_{2} \mathrm{H}_{5}$ & $-\mathrm{CH}_{3}$ \\
\hline
\end{tabular}

Fig. 7. Structures:of pentazocine and analogue benzomorphans used in this study.

Sodium dependency of the uptake. The replacement of $\mathrm{NaCl}$ by choline chloride in the incubation medium had no effect on the uptake of pentazocine by leukocytes. Similarly, no change was observed when $\mathrm{LiCl}$ was substituted for $\mathrm{NaCl}$. Finally, $3 \times 10^{-4} \mathrm{M}$ ouabain had no effect on the transport of pentazocine.

\section{DISCUSSION}

After the observation of the rapid entry of pentazocine into brain after i.p. administration, ${ }^{2}$ the uptake of this compound by a cellular preparation was investigated. Leukocytes were chosen as conveniently available, morphologically typical mammalian cells. If a correlation between biochemical effects observed in leukocytes and those in tissues of organs difficult to access were established, the biochemical investigation of leukocytes, including the determination of drug concentrations in them, could prove a valuable approach in gaining biological information concerning remote areas of the body (e.g. brain).

A valid criticism of our cellular preparation could be its morphological heterogeneity, as it contains various types of leukocytes. However, the characterization of our leukocyte preparation showed no contamination by erythrocytes, a constant ratio of lymphocytes to polymorphonuclear cells and a constant $\mathrm{Na}^{+} / \mathrm{K}^{+}$ratio together with a good reproducibility of the ratio of protein to cell count. The viability of the cells was proven by the linear uptake of oxygen for up to $4 \mathrm{hr}$ of incubation at $37^{\circ}$. The obtained rate of $5-7 \mu 1 \mathrm{O}_{2} / 10^{7} / \mathrm{hr}$ compares favorably with those reported for leukocyte preparations from rabbits ${ }^{6}$ and man. ${ }^{7,8}$

The findings of the present study revealed that pentazocine and analogue benzomorphans accumulate in leukocytes against a concentration gradient. The transport process showed considerable dependence on the presence of glucose and was affected by metabolic inhibitors. In view of the high rate of glycolysis in leukocytes, ${ }^{9}$ it is of 
interest that the strongest inhibition of drug uptake was obtained with iodoacetamide and fluoride, both potent glycolytic inhibitors. It is of further interest that the mean inhibition of the pentazocine transport caused by the latter two compounds (52 and 81 per cent, respectively) correlates well with the average decrease of drug uptake caused by the absence of glucose (64 per cent). The relatively slow recovery of pentazocine transport after the renewed addition of glucose to the depleted cellular preparation (Fig. 5) indicates the necessity of an initial penetration of glucose into the intracellular compartment.

Human blood platelets have been used as a convenient model for the adrenergic neuron. ${ }^{10}$ These blood cells were found to actively accumulate and store organic bases, ${ }^{11,12}$ including biogenic amines such as serotonin and norepinephrine ${ }^{13-15}$ as well as dopamine. ${ }^{16}$ The data from these studies suggest the existence of a relatively nonspecific amine pump in the membrane of the platelet, responsible for the active uptake of the above compounds. In addition to the accumulation against a concentration gradient and its inhibition by metabolic inhibitors, the uptake process of organic bases by platelets was sodium dependent and inhibited by ouabain. ${ }^{12,14}$

As shown by the results presented here, the uptake of pentazocine into leukocytes fulfils the basic criteria for an active transport process. Although preliminary experiments indicated some inhibition of the uptake by epinephrine, detailed experiments in the present study demonstrated that the transport process is independent of sodium and not affected by ouabain. This finding suggests that the transport system for benzomorphans in leukocytes described here is not part of the nonspecific amine pump of the blood platelet. Studies on the structure dependence of the transport system and its species specificity are now in progress.

Acknowledgements-We thank Dr. G. S. Duboff, Department of Internal Medicine and Mr. M. L. Beck, Department of Pathology, for helpful discussion and Dr. E. E. Dekker, Department of Biological Chemistry, for the use of the respirometer. This work was supported in part by United States Public Health Service Grants 5 P11 GM15559 and GM 00187.

\section{REFERENCES}

1. B. A. Berkowitz, J. H. Asling, S. M. Shnider and E. L. Way, Clin. Pharmac. Ther. 10, 320 (1969).

2. F. Medzihradsky and K. Ahmad, Life Sci. 10, 711 (1971).

3. O. H. Lowry, N. J. Rosebrough, A. L. FarR and R. J. Randall, J. biol. Chem. 193, 265 (1951).

4. H. MATTENHEIMER, in Mikromethoden fuer das klinisch-chemische und biochemische Laboratorium, p. 90. Walter de Gruyter, Berlin (1966).

5. K. Ahmad and F. Medzitradsky, Life Sci. 10, 707 (1971).

6. Z. A. CoHn and S. I. Morse, J. exp. Med. 111, 667 (1960).

7. S. K. Bissett and W. D. AleXander, Q. J. exp. Physiol. 46, 50 (1961).

8. M. J. Fallon, E. Frei, III, J. D. Davidson, J. S. Trier and D. Burke, J. Lab. clin. Med. 59, 779 (1962).

9. M. J. Cline, Physiol. Rev. 45, 674 (1965).

10. W. B. Abrams and H. M. Solomon, Clin. Pharmac. Ther. 10, 702 (1969).

11. H. M. Solomon and P. D. Zieve, J. Pharmac. exp. Ther. 55, 112 (1967).

12. R. PocelinKo and H. M. Solomon, Biochem. Pharmac. 19, 697 (1970).

13. R. M. HARDisty and R. S. STACEY, J. Physiol., Lond. 130, 711 (1955).

14. W. B. Abrams, Fedn Proc. 28, 544 (1969).

15. H. M. Solomon, C. Ashley, N. SpirT and W. B. Arrams, Clin. Pharmac. Ther. 10, 229 (1969).

16. H. M. Solomon, N. M. Spirt and W. B. Abrams, Clin. Pharmac. Ther. 11, 838 (1970). 